\title{
Beyond Reasonableness: The Dignitarian Structure of Human and Constitutional Rights
}

\author{
Kai Möller
}

\section{Introduction}

The last two decades have witnessed a wide-ranging and global discussion of the theory and structure of human and constitutional rights. This debate initially focused on the principle of proportionality and subsequently on the related ideas of the 'culture of justification' and the 'right to justification.' There is now a far-reaching agreement that both proportionality and justification in human and constitutional rights law are concerned with the reasonableness, alternatively the justification in terms of public reason, of the act under consideration. Thus, reasonableness and/or public reason have assumed $a$, perhaps the, central place in the theory of human and constitutional rights.

This article challenges this picture as incomplete and unbalanced. The somewhat stale and uninspiring connotations of the concepts of reasonableness and public reason should make us pause and reflect on whether they adequately capture what is important about fundamental rights. Furthermore, an account of rights that places these concepts at its core underemphasises the grand values on which the human rights tradition is built, namely human dignity, freedom, and equality. I will argue that the moral core of human and constitutional rights consists of a commitment not to reasonableness or public reason but to human dignity and its three sub-principles of intrinsic value, moral autonomy, and fundamental equality. Reasonableness has its place in the theory of rights, but it is more peripheral: human and constitutional rights insist that policies and acts be reasonably justifiable under the dignitarian structure which lies at their core.

Section II presents an overview of the development of the theory of human and constitutional rights in the last two decades, which explains how reasonableness and public reason assumed the centrality that they have today. Section III demonstrates that these two concepts cannot do the moral work that is required of them. Section IV presents an outline of the dignitarian structure that lies at the core of human and constitutional rights and shows how this structure manifests itself in rights adjudication. Section $\mathrm{V}$ concludes by showing that shifting the focus from reasonableness to the

\footnotetext{
I presented earlier versions of this article at the 2019 ICON-S conference at the Pontifical Catholic University of Chile in Santiago and the NYU Colloquium in Global and Comparative Public Law, and I am grateful to the participants for their insightful questions and challenges. Furthermore, I would like to thank Conor Gearty, Alon Harel, David Kershaw, Mattias Kumm, Martin Loughlin, Tom Poole, and Joseph Weiler for helpful comments, suggestions, and discussions.

Kai Möller, Professor of Law, Department of Law, London School of Economics \& Political Science, United Kingdom. k.moller@1se.ac.uk
} 
dignitarian structure of rights provides a deeper and more attractive account of the culture of justification and the right to justification.

\section{The Theory of Human and Constitutional Rights: From Formal to Substantive}

Human and constitutional rights theory has flourished since the early 2000 s. ${ }^{1}$ If we had to point to one moment that kicked off this development, it would be the publication of the English translation of Robert Alexy's magisterial $A$ Theory of Constitutional Rights in $2002 .^{2}$ The main achievement of that book was to provide an intriguing theory of the principle of proportionality, which is indisputably the most important doctrinal tool in rights adjudication. Alexy argued that constitutional rights are best conceptualised as principles or optimisation requirements, and that it follows as a matter of logic(!) that proportionality analysis has to be employed when a right gets into conflict with another right or principle. ${ }^{3}$ Alexy's book sparked a wide-ranging debate about the role of the principle of proportionality in rights adjudication that continues until this day. ${ }^{4}$

Despite the strengths of the theory, neither proportionality as such nor Alexy's theory have gone without criticism..$^{5}$ The main weakness of Alexy's theory is that it is formal, or, as Alexy calls it, structural, as opposed to substantively moral. Thus,

1. Up until that point, most scholarship on rights theory was relatively uninterested in and often unaware of the structure and core doctrines of human and constitutional rights law. See Kai Möller, The Global Model of Constitutional Rights (Oxford University Press, 2012) at 2-15 [Möller, The Global Model]. For example, despite its fame and importance, Dworkin's theory of rights as trumps has never really resonated with or been adopted by courts, presumably because its core structural claim - the trumping nature of rights - is hard to reconcile with a judicial practice that regards balancing and proportionality as central. For reinterpretations of Dworkin's theory that reconcile it with balancing and proportionality, see Kai Möller, "Dworkin's Theory of Rights in the Age of Proportionality" (2018) 12:2 Law \& Ethics of Human Rights 281[Möller, "Dworkin's Theory of Rights"]; Jacob Weinrib, Dimensions of Dignity: The Theory and Practice of Modern Constitutional Law (Cambridge University Press, 2016) at 245-51.

2. Robert Alexy, A Theory of Constitutional Rights, translated by Julian Rivers (Oxford University Press, 2002).

3. Ibid, ch 3 .

4. See e.g. the following edited collections: Grant Huscroft, Bradley W Miller, \& Grégoire Webber, eds, Proportionality and the Rule of Law-Rights, Justification, Reasoning (Cambridge University Press, 2014); Vicki C Jackson \& Mark Tushnet, eds, Proportionality: New Frontiers, New Challenges (Cambridge University Press, 2017). Other central contributions include Aharon Barak, Proportionality: Constitutional Rights and their Limitations (Cambridge University Press, 2012); David M Beatty, The Ultimate Rule of Law (Oxford University Press, 2005); Dieter Grimm, "Proportionality in Canadian and German Constitutional Jurisprudence" (2007) 57:2 UTLJ 383; Mattias Kumm, "Constitutional rights as principles: On the structure and domain of constitutional justice" (2004) 2:3 Int'1 J Constitutional Law 574; Mattias Kumm, "Political Liberalism and the Structure of Rights: On the Place and Limits of the Proportionality Requirement" in G Pavlakos, ed, Law, Rights and Discourse: The Legal Philosophy of Robert Alexy (Hart, 2007) 131 [Kumm, "Political Liberalism"]; Kai Möller, "Proportionality: Challenging the Critics" (2012) 10:3 Int'1 J Constitutional Law 709.

5. See in particular Stavros Tsakyrakis, "Proportionality: An assault on human rights?" (2009) 7:3 Int'1 J Constitutional Law 468; Grégoire CN Webber, The Negotiable Constitution: On the Limitation of Rights (Cambridge University Press, 2009); Francisco J Urbina, "Is it Really That Easy? A Critique of Proportionality and 'Balancing as Reasoning”' (2014) 27:1 Can JL \& Jur 167. 
the language that Alexy uses is one of 'rules,' 'principles,' 'optimisation,' 'logic,' and so on. The problem with this approach is that, as I have argued elsewhere, ${ }^{6}$ fundamental rights are creatures of morality and therefore a useful account of their structure must be a moral one. Thus, while the more recent scholarship on the theory of human and constitutional rights builds on and is indebted to Alexy's work (more on this below), by and large, ${ }^{7}$ the search for a formal theory has been abandoned and instead substantively moral accounts of rights are proposed.

If Alexy's book marks the 'first wave' of scholarship theorising proportionality-based judicial review, then a number of publications by various scholars writing about the 'culture of justification' and the related idea of the 'right to justification' can be referred to as the 'second wave. ${ }^{8}$ The term 'culture of justification,' originally coined by the South African public law scholar Etienne Mureinik, ${ }^{9}$ refers to a constitutional culture (a better term might be 'constitutional structure') that acknowledges every citizen's right to challenge any policy or act by the state that places a burden on him or her before the courts and ultimately the constitutional court; the main doctrinal tool that courts will use to assess the justifiability of the policy or act in question is, again, proportionality. ${ }^{10}$

Thus, the culture of justification — which has been called the "emerging global legal culture" by Iddo Porat and Moshe Cohen-Eliya ${ }^{11}$ —rejects a number of conventional views about human and constitutional rights. First, it rejects the view that rights protect only a limited domain of narrowly defined interests (such as interests relating to speech, religion, life, freedom from torture, etc.); on the contrary, the culture of justification claims that any burden, including trivial ones, should be reviewable by, ultimately, the constitutional court. ${ }^{12}$ Doctrinally, this is achieved by either acknowledging a general right to liberty or freedom of action (as in the case of the German Federal Constitutional Court ${ }^{13}$ ) or by interpreting certain rights, in particular the right to private life, very broadly (as in the

6. Kai Möller, "Balancing and the structure of constitutional rights" (2007) 5:3 Int'1 J Constitutional Law 453.

7. An exception is Matthias Klatt \& Moritz Meister, The Constitutional Structure of Proportionality (Oxford University Press, 2012).

8. Key publications here are David Dyzenhaus, "Proportionality and Deference in a Culture of Justification" in G Huscroft, BW Miller, \& G Webber, eds, Proportionality and the Rule of Law_Rights, Justification, Reasoning (Cambridge University Press, 2014) 234; Mattias Kumm, "The Idea of Socratic Contestation and the Right to Justification: The Point of Rights-Based Proportionality Review" (2010) 4:2 Law \& Ethics of Human Rights 141; Möller, The Global Model, supra note 1; Kai Möller, "Justifying the Culture of Justification" (2019) 17:4 Int'l J Constitutional Law 1078 [Möller, "Justifying the Culture"]; Moshe Cohen-Eliya \& Iddo Porat, Proportionality and Constitutional Culture (Cambridge University Press, 2013).

9. Etienne Mureinik, "A Bridge to Where? Introducing the Interim Bill of Rights" (1994) 10:1 SAJHR 31 at 32. See further David Dyzenhaus, "Law as Justification: Etienne Mureinik's Conception of Legal Culture" (1998) 14:1 SAJHR 11.

10. See Möller, "Justifying the Culture", supra note 8 at 1078-79.

11. Cohen-Eliya \& Porat, supra note 8 at 7.

12. Ibid at 119; Möller, "Justifying the Culture", supra note 8 at 1083.

13. BVerfGE 6, 32-Elfes (1957); BVerfGE 54, 143-Ban on Pigeon-Feeding (1980); BVerfGE 80, 137-Riding in the Woods (1989). 
case of the European Court of Human Rights ${ }^{14}$ ). The effect of this is that a great number of state acts interfere with a protected right and thus trigger the duty of justification and proportionality analysis. Incidentally, this sits neatly with Alexy's theory of rights which, too, endorses the German Federal Constitutional Court's acknowledgment of a general right to liberty and thus rejects the conventional view about the limited scope of rights. ${ }^{15}$

Second, the culture of justification does away with a widely held view according to which rights have a special normative force in the sense that their limitation can only exceptionally be justified. This view arguably underlies much of U.S. constitutional jurisprudence and in particular its 'strict scrutiny' test. As the saying goes, strict scrutiny is "strict in theory but fatal in fact," 16 indicating that it is an uphill battle for the state to convince a court of the necessity of the limitation of a fundamental right. Furthermore, and glossing over some complications, such a view can be attributed to Ronald Dworkin's theory of rights as trumps, ${ }^{17}$ which at least superficially contrasts with Alexy's view of rights as optimisation requirements. ${ }^{18}$ Instead, the culture of justification requires only that the state act in question be 'justifiable.' The tool used to assess justifiability is proportionality, and proportionality in turn is seen by the culture of justification as a test of reasonableness and/or public reason. ${ }^{19}$

The moral foundation of the culture of justification is seen in every person's fundamental 'right to justification,' that is, the right to be subjected to the coercive power of the state only when this is substantively justifiable. The most fully developed account of this is Mattias Kumm's theory of rights adjudication as Socratic contestation. ${ }^{20} \mathrm{Kumm}$ argues that the right to justification is as fundamental as the right to vote. The key to understanding the interplay between the two lies in the idea of reasonable disagreement. Democratic (in the sense of majoritarian) voting is about choosing between different reasonably justifiable policies; the role of judicial review is to police the boundaries of this process, that is, to ensure that the chosen policy is indeed reasonably justifiable to those on whom it imposes a burden and respects their right to justification. Thus, a court engaging in judicial review does not ask the question of whether the policy at stake is 'right,' 'correct,' or 'the best possible policy'; rather it asks whether it is reasonably justifiable, or, synonymously for Kumm, justifiable in terms of

14. See George Letsas, A Theory of Interpretation of the European Convention on Human Rights (Oxford University Press, 2007) at 126-30.

15. Alexy, supra note 2 at ch 7.

16. Gerald Gunther, "The Supreme Court 1971 Term-Forward: In Search of Evolving Doctrine on a Changing Court: A Model for a Newer Equal Protection" (1972) 86:1 Harv L Rev 1 at 8.

17. For an early statement, see Ronald Dworkin, "Rights as Trumps" in J Waldron, ed, Theories of Rights (Oxford University Press, 1984) 153. For his later work, see Ronald Dworkin, Is Democracy Possible Here? Principles for a New Political Debate (Princeton University Press, 2006) at 31 [Dworkin, Is Democracy Possible Here?].

18. For views that challenge this picture, see Möller, "Dworkin's Theory of Rights", supra note 1; Weinrib, supra note 1.

19. Cohen-Eliya \& Porat, supra note 8 at 112; Kumm, supra note 8 at 168-70; Möller, "Justifying the Culture", supra note 8 at 1089-92.

20. Kumm, supra note 8 . 
public reason; only if it is not justifiable in this way does the court reach the conclusion that it violates rights. The tool that courts use to carry out this assessment is proportionality, which accordingly is conceptualised as a test of public reason.

Thus, if we look at the development between the first and the second 'waves' of human and constitutional rights scholarship, we see that several of Alexy's insights are carried over - in particular the centrality, practical usefulness, and structure of the principle of proportionality, the commitment to the wide scope of rights, and the rejection of the view that rights have a special normative force. However, the 'second wave' scholars abandon Alexy's commitment to formal theories of rights. Rights theory goes substantive and a view about the moral point of rights is articulated, namely to protect every person's right to justification; the scope of rights and the appropriate standard of review (proportionality as a reasonableness review) are derived from this moral starting point. In the next section I will argue that while this is an improvement over Alexy's theory, it is incomplete. As I will show, the concepts of 'reasonableness,' 'reasonable disagreement,' and 'public reason' cannot do what is required of them if our goal is to give a fully-fledged moral account of human and constitutional rights.

\section{Reasonableness, Reasonable Disagreement, and Public Reason}

This section demonstrates that a theory of rights that presents as its core a commitment to reasonableness and/or justifiability in terms of public reason is incomplete. The first subsection examines the concept of reasonableness. The second subsection proposes what I call 'the procedural conception of reasonableness' and shows that this conception is broader than the standard of review properly used in human and constitutional rights law. The third subsection shows that this gap cannot be closed by invoking the concept of public reason. The fourth subsection concludes that the commitment to reasonableness or public reason must be complemented with a further commitment to a number of substantive values and suggests that these values can be found in the dignitarian structure of human and constitutional rights.

\section{The concept of reasonableness}

Reasonableness is a concept widely used in different areas of law as well as in philosophy, but it is not easy to define. According to Alexy, the idea of reasonableness "requires, first, that all factors that might be relevant in answering a practical question be considered and, second, that they be assembled in a correct relation to each other in order to justify the judgment that provides the answer." 21 The famous English Wednesbury case lays out a similar structure:

I will summarize once again the principle applicable. The court is entitled to investigate the action of the local authority with a view to seeing whether they have taken

21. Robert Alexy, "The Reasonableness of Law" in G Bongiovanni, G Sartor, \& C Valentini, eds, Reasonableness and Law (Springer, 2009) 5 at 7. 
into account matters which they ought not to take into account, or, conversely, have refused to take into account or neglected to take into account matters which they ought to take into account. Once that question is answered in favour of the local authority, it may be still possible to say that, although the local authority have kept within the four corners of the matters which they ought to consider, they have nevertheless come to a conclusion so unreasonable that no reasonable authority could ever have come to it. In such a case, again, I think the court can interfere. ${ }^{22}$

Collecting the relevant (and excluding the irrelevant) considerations and then identifying the correct relation of these considerations strikes me as the right approach in principle. The practical problem, of course, lies in the fact that often, it will be far from obvious what the relevant considerations are and what their correct relation really is. The judges in the Wednesbury case fell into the trap of circularity when they defined reasonableness with regard to the view that a 'reasonable authority' could take: this just shifts the problem from the decision to the person or body making the decision. In the next subsection I will present a procedural account of reasonableness that avoids this problem.

Leaving aside the conceptual complications, a couple of things can be said about reasonableness in public law, including rights adjudication. The first is that insisting that a decision be reasonable (or reasonably justifiable) excludes non-reason-based justifications. Thus, mere reference to tradition ('We have always done things this way!'), pedigree ('It's justified because the public authority/the legislature/the framers said so!'), feelings ('In this town, we just love/hate opera!'), etc., is insufficient; rather, a justification can only succeed if based on reason. (Needless to say, it may sometimes be the case that tradition, pedigree, or feelings play a role in the determination of the reasonableness of a decision; for example, the fact that a certain tradition exists may be relevant in determining whether there are good reasons for its continuation, or the fact that a large number of people like or dislike a certain option may be relevant in deciding about its adoption.)

Second, in public law, reference to reasonableness is coupled with an acknowledgement of the relevance of reasonable disagreement, that is, the fact that reasonable people will often disagree about the right course of action. Thus, reasonableness review indicates that the courts will not inquire whether the public authority in question reached the 'right,' 'best possible,' or 'correct' decision; rather they will only inquire whether the decision is one of (usually) a range of decisions that can be considered reasonable. The Wednesbury court stressed this point:

I think Mr. Gallop in the end agreed that his proposition that the decision of the local authority can be upset if it is proved to be unreasonable, really meant that it must be proved to be unreasonable in the sense that the court considers it to be a decision that no reasonable body could have come to. It is not what the court considers unreasonable, a different thing altogether. If it is what the court considers unreasonable, the court may very well have different views to that of a local authority on

22. Associated Provincial Picture Houses, Limited v Wednesbury Corporation, [1948] 1 KB 223 (EWCA) at 233-34 [Wednesbury]. 
matters of high public policy of this kind. Some courts might think that no children ought to be admitted on Sundays at all, some courts might think the reverse, and all over the country I have no doubt on a thing of that sort honest and sincere people hold different views. The effect of the legislation is not to set up the court as an arbiter of the correctness of one view over another. ${ }^{23}$

The same is true today in rights adjudication, where courts applying the proportionality test regularly stress that their role is not to second-guess the original decision but merely to assess its proportionality or reasonableness, which is a wider standard than correctness. ${ }^{24}$ Thus, it strikes me as correct to say that there is no principled difference between Wednesbury reasonableness and proportionality in that both tests are concerned with the reasonableness of the act under consideration, and that the main practical difference is that proportionality tends to be applied with less deference than Wednesbury reasonableness. ${ }^{25}$

The above points regarding the focus on reason and the acknowledgment of the relevance of reasonable disagreement are important guidelines in the context of human and constitutional rights adjudication. However, both are negative in character in that they do not point to a substantive content of reasonableness but merely exclude non-reason-based standards and a correctness standard of review, without specifying positively what the standard to be applied actually is.

\section{The procedural conception of reasonableness}

To avoid the problem of defining the reasonableness of a decision by referring to the reasonable decision-maker, I wish to propose the following, procedural, conception of reasonableness: we should regard as reasonable a view that an educated and intelligent person, acting in good faith and after due reflection, could consider to be true. ${ }^{26}$ The requirements of 'educated and intelligent' replace reference to the 'reasonable' person, in order to avoid the circularity problem mentioned above. I call this conception 'procedural' because it has no substantive requirements with regard to the view in question but only procedural ones: any view, no matter what its content, is regarded as reasonable if it survives a process of careful and good faith reflection by an educated and intelligent person. I should also add that my definition could well be regarded as too demanding: surely people who are not particularly intelligent or well-educated will also regularly arrive

23. Ibid at 230-31.

24. Aileen Kavanagh, Constitutional Review under the UK Human Rights Act (Cambridge University Press, 2009) at 240.

25. See Ibid at 243-53; Möller, "Justifying the Culture", supra note 8 at $1091 \mathrm{n} 38$; Thomas M Poole \& Sangeeta Shah, "A Very Successful Action? Historical Wrongs at Common Law" LSE Legal Studies Working Paper No. 17/2016 at 17-20, online at https://papers.ssrn.com/ sol3/papers.cfm?abstract_id=2869840. For the judicial discussion of this issue and broadly similar conclusions, see $R$ (Daly) $v$ Secretary of State for the Home Department, [2001] UKHL 26 at para 27; Pham v Secretary of State for the Home Department, [2015] UKSC 19 at paras 103-09.

26. Note that the Wednesbury court comes close to this when in the quote above it refers to the fact that "honest and sincere people hold different views." 'Honest and sincere' avoids the circularity problem. 
at reasonable conclusions. The point of setting the bar relatively high is not elitism but preparing the ground for demonstrating that even this, demanding, account of reasonableness is too wide in the context of rights adjudication.

I will proceed to show that the procedural conception of reasonableness would characterise a whole range of views as reasonable that relatively uncontroversially are incompatible with the requirements of human and constitutional rights. Before I give examples, a note of caution is in order: there is the risk that we smuggle a set of substantive convictions about the scope of reasonableness into the procedural conception by claiming that surely, an 'adequately' intelligent person, after 'due' reflection and acting in 'genuinely' good faith could never hold this or that view. The procedural account of reasonableness properly understood blocks this route, precisely because of its procedural nature. It does not allow us to question on substantive grounds the outcome reached.

Here are three examples of views that are reasonable (under the procedural account) and yet relatively uncontroversially (and to my mind, correctly) considered to violate rights. Each example is an application of one of the dignitarian principles that I will introduce in the next section.

First, take the example of the permissibility of torture as a measure to prevent terrorist attacks. The large majority of human and constitutional rights lawyers consider torture to be legally and morally unjustifiable in all circumstances. ${ }^{27}$ However, Alan Dershowitz (and others) have argued that in extreme circumstances torture can be justified if the benefits outweigh the costs. ${ }^{28}$ Given that Dershowitz is an established academic, obviously well-educated and intelligent, who has thought about this issue with considerable care, and given that we have no reason to question his good faith, it follows that we must regard his views as reasonable under the procedural conception of reasonableness. If we are also attached to the view that torture violates rights, then we have established a gap between the procedural conception of reasonableness and the requirements of rights. As I will show below, the reason for this gap is that human and constitutional rights are committed to upholding the dignitarian idea of the intrinsic value of each individual, which is inconsistent with torture, whereas procedural reasonableness has no such inbuilt substantive requirement.

Second, let us consider the example of assisted suicide. I do not have in mind the issue of whether, all things considered, terminally ill people who are no longer capable of killing themselves without assistance have a right to assisted suicide. Rather, my interest here is in one particular facet of this debate, namely the question of whether assisted suicide can be prohibited by pointing to the fact that the state has a legitimate interest in preserving human life. This is a widely used

27. See e.g. the European Court of Human Rights view in the Gäfgen case: "The Court has confirmed that even in the most difficult circumstances, such as the fight against terrorism and organised crime, the Convention prohibits in absolute terms torture and inhuman or degrading treatment or punishment, irrespective of the conduct of the person concerned." Gäfgen v Germany (2011) 52 EHRR 1 at para 87.

28. Alan M Dershowitz, Why Terrorism Works: Understanding the Threat, Responding to the Challenge (Yale University Press, 2003) at 132-63. 
argument in the debate about assisted suicide; for example, the (now) US Supreme Court Justice Neil Gorsuch proposed a version of this argument in his book The Future of Assisted Suicide and Euthanasia, where he argued that human life is inherently valuable and that its intentional taking by private persons is always wrong. ${ }^{29}$ Gorsuch is intelligent and educated (he has a doctorate from Oxford which formed the basis of his book), and there is nothing to indicate that he has not thought about this issue for a long time and in good faith. Hence, his view passes as reasonable under the procedural conception of reasonableness. However, courts have, by and large $\mathrm{e}^{30}$ and to my mind correctly, rejected the argument from the intrinsic value of human life and pointed out that it would be inappropriate to disregard the perspective of the person whose life it is ${ }^{31}$ the permissibility of assisted suicide then turns on other factors, such as the likelihood of abuse. Thus, there is yet another gap between procedural reasonableness and the requirements of rights which, as the next section will show, is best explained by the dignitarian principle of moral autonomy.

My third example is same-sex marriage. I assume that the view increasingly taken by liberal democracies, namely that rights require the availability of same

29. Neil M Gorsuch, The Future of Assisted Suicide and Euthanasia (Princeton University Press, 2006) ch 9 .

30. An exception is the US Supreme Court, which has accepted by a 5:4 majority the argument that the state has an unqualified interest in the preservation of human life. See Cruzan v Director, Missouri Department of Health (1990), 497 US 261 at 282: "Finally, we think a State may properly decline to make judgments about the 'quality' of life that a particular individual may enjoy, and simply assert an unqualified interest in the preservation of human life to be weighed against the constitutionally protected interests of the individual." See, however, the dissent by Brennan, Marshall, and Blackmun JJ, at 314: "Thus, the State's general interest in life must accede to Nancy Cruzan's particularized and intense interest in self-determination in her choice of medical treatment. There is simply nothing legitimately within the State's purview to be gained by superseding her decision." See further Stevens J, also in dissent, at 345: "The State's unflagging determination to perpetuate Nancy Cruzan's physical existence is comprehensible only as an effort to define life's meaning, not as an attempt to preserve its sanctity."

31. This has recently been pointed out most strikingly and clearly by the German Federal Constitutional Court in a judgment which declared the criminalisation of assisted suicide services unconstitutional: "The general right of personality ... encompasses a right to a self-determined death. This right includes the freedom to take one's own life ... Where, in the exercise of this right, an individual decides to end their own life, having reached this decision based on how they personally define quality of life and a meaningful existence, their decision must, in principle, be respected by state and society as an act of autonomous self-determination." See judgment (in German), online at https://www.bundesverfassungsgericht.de/SharedDocs/Entscheidungen/DE/ 2020/02/rs20200226_2bvr234715.html). See "Criminalisation of assisted suicide services unconstitutional: Press Release No. 12/2020" (February 26, 2020), online at https://www. bundesverfassungsgericht.de/SharedDocs/Pressemitteilungen/EN/2020/bvg20-012.html;jsessio nid=68998647AF09E565F22C29C47D9628E7.1_cid370. See further Pretty v United Kingdom (2002), 35 EHRR 1 at para 65: "The very essence of the Convention is respect for human dignity and human freedom. Without in any way negating the principle of sanctity of life protected under the Convention, the Court considers that it is under Article 8 that notions of the quality of life take on significance. In an era of growing medical sophistication combined with longer life expectancies, many people are concerned that they should not be forced to linger on in old age or in states of advanced physical or mental decrepitude which conflict with strongly held ideas of self and personal identity"; Carter v Canada (Attorney General), [2015] 1 SCR 331 at para 63: "This said, we do not agree that ... individuals cannot 'waive' their right to life. This would create a 'duty to live,' rather than a 'right to life."” 
sex marriage, ${ }^{32}$ is correct. Just as in the case of torture, however, the issue of same sex marriage is very controversial. The philosopher John Finnis is well known for his opposition to same sex marriage, which is grounded in his famous theory of natural law and natural rights; he argues that "[s]ince the sexual acts of same-sex partners (couples, threesomes, foursomes ... ) have no tendency at all to generate children, there is no reason why whatever commitment such partners wish to make to one another (as couples, threesomes, foursomes ... for life or for five years ... ) should be thought of as marriage." 33 Now, fortunately for my argument, Finnis is a famous philosopher; we have no reason, therefore, to question his intelligence or willingness to engage in serious reflection. We might consider questioning his good faith on this issue (and find some evidence for this in the derisive tone of the above statement: "couples, threesomes, foursomes"; "for life or for five years"); but if all scholarship which displayed an element of neurotic involvement on the part of the author was considered to be produced in bad faith, there would perhaps not be much left to take seriously. Note also that we cannot derive the existence of bad faith from the fact that we disagree with a person's substantive view. Therefore, I believe that under the procedural view of reasonableness, Finnis' rejection of same sex marriage easily passes the threshold and must be considered reasonable. Thus, if we maintain that the availability of same sex marriage is a matter of rights, then there is a gap between procedural reasonableness and the requirements of rights. I will argue below that the reason for this gap lies in the dignitarian principle of fundamental equality.

\section{Public reason}

Mattias Kumm has proposed that human and constitutional rights require the justification of any act that places a burden on a person in terms of public reason. He argues that proportionality analysis is

largely an exercise of structured practical reasoning without many of the constraining features that otherwise characterizes legal reasoning ... The proportionality test merely provides a structure for the demonstrable justification of an act in terms of reasons that are appropriate in a liberal democracy. Or to put it another way: It provides a structure for the justification of an act in terms of public reason. ${ }^{34}$

32. Same sex marriage was in many cases legalised through the normal legislative processes. For judicial decisions to this effect, see in particular Obergefell v Hodges (2015), 135 S. Ct. 2584 (US); Minister of Home Affairs v Fourie, [2005] ZACC 19 (S Afr Const Ct); Interpretation No. 748 (2017) (Judicial Yuan). The European Court of Human Rights' position is that there is not yet sufficient consensus within the member states to allow a re-interpretation of Article 12 ECHR: Schalk \& Kopf v Austria (2011), 53 EHRR 20 at para 58. However, in Oliari \& Others $v$ Italy (2017), 65 EHRR 26, the Court found a positive obligation on the Italian authorities to create a legal framework providing for the recognition and protection of same sex unions.

33. John Finnis, Human Rights \& Common Good: Collected Essays: Volume III (Oxford University Press, 2011) at 326.

34. Kumm, supra note 8 at 150 [emphases omitted]. 
Thus, the invocation of the idea of public reason highlights two features of reasoning with rights. First, it stresses that rights adjudication is not concerned with conventional ways of legal reasoning (those that focus on the interpretation of a legal source) but rather with 'free-standing' practical reasoning (Kumm calls this "the turn from interpretation to justification" ${ }^{35}$ ). Second, the practical reasoning is constrained in that only reasons that are "appropriate in a liberal democracy" (and therefore 'public') are legitimate. This implies that some reasons are not appropriate in a liberal democracy (and correspondingly not 'public'), namely, in particular, perfectionist reasons relating to the good life. (Here Kumm's thinking is influenced by John Rawls' account of public reason, even though Kumm makes it clear that he does not subscribe to Rawls' theory in its entirety. ${ }^{36}$ ) The paradigmatic case of such impermissible reasons is religious reasons: in another paper, Kumm gives the example of a public authority justifying the introduction of compulsory school prayers by referring to the necessity of creating "souls worthy of salvation." 37

As a preliminary point, both the usefulness of the idea of public reason and its proper interpretation are a matter of fierce philosophical debate, which is of limited relevance in the context of rights adjudication and therefore not my interest in this paper. However, there is also a separate discussion about the usefulness of the idea of public reason specifically in rights adjudication. Jeremy Waldron, a sceptic in this regard, has argued that the idea of public reason should be seen as requiring that reasons must be offered "as something for others to grasp, consider, and engage with" ${ }^{38}$ (and he then claims that even religious reasons can be offered in this spirit; holding otherwise "underestimates people's ability to grapple with unfamiliar views that start out with no foothold in their own mentality or motivational set" ${ }^{39}$ ). Wojciech Sadurski has criticised Waldron's approach and insisted that an idea should not only be "graspable" but also "endorseable" by others, which narrows the range of acceptable reasons and excludes religious ones. ${ }^{40} \mathrm{I}$ will work with Sadurski's narrower interpretation when assessing Kumm's claims.

I have two concerns about Kumm's invocation of the idea of public reason. First, I believe that the actual concern at the heart of Kumm's argument is not for the publicness of the reasons given but for the dignitarian principle of moral autonomy (on which more in the next section). I agree with Kumm's claim, which is widely endorsed in liberal philosophy, ${ }^{41}$ that rights require that states abstain from imposing perfectionist ideals on their citizens. But I don't think that

35. Ibid at 144 .

36. Ibid at $150 \mathrm{n} 16$.

37. Kumm, "Political Liberalism", supra note 4 at 143.

38. Jeremy Waldron, "Public Reason and 'Justification' in the Courtroom" (2007) 1:1 Journal of Law, Philosophy \& Culture 107 at 112.

39. Ibid.

40. Wojciech Sadurski, "Defending Public Reason" (2014) Sydney Law School Research Paper No. 14/31 at 2, online at https://papers.ssrn.com/sol3/papers.cfm?abstract_id=2410718.

41. For a comprehensive discussion of this issue, see Jonathan Quong, Liberalism Without Perfection (Oxford University Press, 2011). For the context of rights adjudication, see Letsas, supra note 14 at ch 6. 
the reason for this is that perfectionist policies violate a requirement of publicness: almost all views, including those that violate liberal neutrality, can be put forward in a language that does not rest on controversial ethical viewpoints and is therefore 'endorseable' (in Sadurski's terminology). To illustrate the point, let us take Kumm's example of compulsory school prayers. I will grant that the reason of 'creating souls worthy of salvation' is not 'public.' But if the authority made the same point in a secular language, its 'public' nature would be difficult to deny. Assume the authority argues that "compulsory school prayers create a sense of community and are thus desirable from a developmental perspective; they contribute to making the students more well-balanced." There are all kinds of critical questions we could ask about this reasoning ("Is it empirically true?" "Is there evidence?" "Are there alternatives?"), but it would be a stretch to deny its 'publicness': the reasoning employed by the authority could in principle be endorsed by members of many different ethical (including religious) convictions. The real problem with compulsory school prayers is that they violate the students' autonomy in religious matters (or the rights of their parents to educate them in line with their own religious convictions). Thus, the concern is for the dignitarian principle of moral autonomy, not the publicness of the reasons given.

Second, while a commitment to the idea of justifiability in terms of public reason, as opposed to procedural reasonableness, may narrow the gap between procedural reasonableness and the demands of human and constitutional rights, it does not close it. At best (and ignoring my criticism in the previous paragraph), the commitment to public reason excludes perfectionist reasons, such as religious reasons. But this is not enough. Take the above example of allowing torture in extreme cases. ${ }^{42}$ Proponents of this idea point to the gains in security that in their view can be achieved by using torture and argue that these gains should be balanced against the interests of terrorist suspects. This argument is entirely 'public' and yet, the near-consensus among courts and rights scholars is, to my mind correctly, that torture is impermissible in all cases. Thus, there is more to the moral structure of human and constitutional rights than a commitment to public reason.

To this conclusion it could be objected that public reason should not be seen as primarily concerned, negatively, with the exclusion of certain reasons (for example, reasons that are not 'graspable or 'endorseable' by everyone) but that the concept should rather be seen to refer, positively, to reasons which are appropriate among free and equal citizens. For example, compulsory school prayers should be regarded as unjustifiable in terms of public reason because they are inconsistent with the students' freedom; a discriminatory policy should be seen as unjustifiable in terms of public reason because it is inconsistent with each citizen's equality. I have no substantive objection to this conceptualisation of public reason but doubt its necessity in the context of rights adjudication: we could invoke the values of freedom and equality directly and without the intermediate concept

42. See Section III.2, above. 
of public reason. So rather than suggesting, as Kumm does, that policies need to be 'justifiable in terms of public reason,' it would be more to the point to say that they need to be 'justifiable in terms of freedom and equality.' This is broadly the route that I will pursue in Section IV, where I will argue that policies must be justifiable in light of the dignitarian principles of intrinsic value, moral autonomy, and fundamental equality.

\section{A thicker conception of reasonableness?}

As I have demonstrated in subsection 2, a procedural understanding of reasonableness is too wide in the context of rights adjudication: rights prohibit some policies which are reasonable in the procedural sense. The idea of public reason as employed by Kumm at best narrows the gap somewhat but it does not close it unless one reads a commitment to freedom and equality into it. If procedural reasonableness and public reason cannot do the necessary moral work, perhaps a thicker, substantive, conception of reasonableness could? For example, John Rawls relied heavily on the idea of reasonable people, especially in his book Political Liberalism. He specified a number of features and characteristics of such people, which include them having a sense of justice, being ready to propose fair terms of cooperation, recognising the burdens of judgment, and affirming only reasonable comprehensive doctrines. ${ }^{43}$ Maybe Rawls' or another, thicker, conception of reasonableness could succeed in making sense of the moral structure of constitutional rights.

My goal in this essay is to demonstrate that human and constitutional rights have a substantive moral core and to articulate its content. I do not dispute that it may be possible to read this core into a substantive conception of reasonableness and/or public reason. Note, though, that this has not yet been attempted in human and constitutional rights scholarship: none of the literature on the culture of justification, the right to justification, or proportionality which proposes to regard rights and/or proportionality as concerned with reasonableness or justifiability in terms of public reason has put forward a substantive conception of reasonableness. Therefore, any evaluation of the success of this route will have to wait. As I have pointed out above, I believe that there is a certain staleness about the language of reasonableness and public reason which fails to capture what is important about human and constitutional rights, and furthermore I think that the human rights tradition lends support to seeing dignity, freedom, and equality, as opposed to reasonableness, as the moral core of rights. Therefore, I will not pursue my project of articulating the substantive core of rights by refining the concept of reasonableness but rather by turning to the idea of human dignity.

43. John Rawls, Political Liberalism, 2nd ed (Columbia University Press, 2005) at 81-86. 


\section{The Dignitarian Structure of Human and Constitutional Rights}

The previous section has shown that while the theory of human and constitutional rights needs the idea of reasonableness, rights also include certain substantive commitments that cannot be explained in the language of (procedural) reasonableness alone. This section proposes an account of these substantive commitments by introducing what I call the dignitarian structure of human and constitutional rights.

The concept of human dignity captures and expresses the idea of the supreme value of the individual human being; but beyond this starting point, much is unclear and contested. My goal in this essay is not to present a new theory of dignity, nor is it to engage in a comprehensive analysis of the existing literature on human dignity. Rather, my more modest ambition is to identify three reasonably uncontroversial yet central facets of human dignity and to show how these manifest themselves in the practice and structure of human and constitutional rights law. The three facets that I will focus on are, first, the intrinsic value of every individual, second, the individual's moral autonomy, and third, his or her their fundamental equality. My claim is that these three principles form the moral 'deep structure' of human and constitutional rights.

There are similarities with Ronald Dworkin's account of dignity here. Dworkin's influence is perhaps not surprising, given that he spent much of his life theorising rights and came to regard human dignity as their foundation. ${ }^{44}$ In his late work, especially in his books Is Democracy Possible Here? and Justice for Hedgehogs, he argued that human dignity consists of two principles, which he called the principle of intrinsic value and the principle of personal responsibility (more on these below). For present purposes, I chose to divide his principle of intrinsic value (which, for Dworkin, includes a commitment to the equal value of every human life) into two, which I call the principle of intrinsic value and the principle of fundamental equality. As will become clear, this makes analytical and moral sense, and the two principles illuminate different facets of contemporary human and constitutional rights law. I should also state at the outset that I disagree with a number of Dworkin's views on rights and dignity, and this section should not be read as an exercise in Dworkin scholarship. Interested readers are directed to an earlier paper in which I offer a re-interpretation of Dworkin's theory of rights. ${ }^{45}$

44. In his earlier work, Dworkin regarded a right to equal concern and respect as foundational. See Ronald Dworkin, Taking Rights Seriously (Harvard University Press, 1977), at 272-73. In his later work, he introduced the idea of dignity as the foundation of rights. The idea of equal concern reappeared as the principle of intrinsic value (the first principle of human dignity) and the idea of equal respect became the principle of personal responsibility (the second principle of human dignity). See Dworkin, Is Democracy Possible Here?, supra note 17 at 32 . The centrality of human dignity is explained in Ronald Dworkin, Justice for Hedgehogs (Harvard University Press, 2011) at ch 9.

45. Möller, "Dworkin's Theory of Rights", supra note 1. 


\section{Intrinsic value}

While it is extremely difficult to come up with a definition or conception of human dignity, there is some, limited, consensus about its meaning. In his path-breaking study "Human Dignity and Judicial Interpretation of Human Rights," Christopher McCrudden concluded that there is a "minimum core" to human dignity, which includes the claims that, first, every human being possesses an intrinsic worth, second, this worth should be recognised and respected by others, and third, recognising and respecting this worth requires that the state should be seen to exist for the sake of the individual human being rather than vice versa. ${ }^{46}$ The idea of intrinsic worth also appears in a modified form in Dworkin's account of human dignity: "The first principle [of human dignity] which I shall call the principle of intrinsic value-holds that each human life has a special kind of objective value. It has value as potentiality; once a human life has begun, it matters how it goes." 47

The claim that human lives have intrinsic value is very abstract, and its moral and legal implications are not obvious. While it would be imprudent to try to resolve this puzzle in the limited space available here, I would like to point out the direction that a more fully formed conception of the idea of intrinsic value would have to take by briefly engaging with Jeremy Waldron's and Susanne Baer's accounts of human dignity and clarifying how their ideas illuminate features of contemporary rights discourse.

Waldron proposes to make the idea of human dignity operable by regarding it not as a value (to be balanced against other values) but as a high status or rank:

A good account of human dignity will explain it as a very general status. But it will also generate an account of it as noble bearing and an account of the importance of the ban on humiliating and degrading treatment. That is what I am trying to do with an account of dignity as a high-ranking status, comparable to a rank of nobilityonly a rank assigned now to every human person, equally without discrimination: dignity as nobility for the common man. ${ }^{48}$

Thus, under this approach we honour the intrinsic value of each person by treating them like a noble, as opposed to, for example, a slave; and it goes without saying that a noble will be treated as a person of the highest importance.

Baer interprets the intrinsic value idea differently, namely as being about "the promise of recognition of diverse senses of self, as deserving of equal respect." 49 Here, the intrinsic worth of each person requires first and foremost that others

46. Christopher McCrudden, "Human Dignity and Judicial Interpretation of Human Rights," (2008) 19:4 Eur J Intl L 655 at 679. On the centrality of the idea of intrinsic value, see also Michael Rosen, "Dignity Past and Present" in J Waldron, Dignity, Rank, and Rights, edited by Meir Dan-Cohen (Oxford University Press, 2012) 79 at 86.

47. Dworkin, Is Democracy Possible Here?, supra note 17 at 9.

48. Jeremy Waldron, Dignity, Rank, and Rights, edited by Meir Dan-Cohen (Oxford University Press, 2012) at 22.

49. Susanne Baer, "Dignity, Liberty, Equality: A Fundamental Rights Triangle of Constitutionalism," (2009) 59:4 UTLJ 417 at 460. 
look carefully at the person and all aspects of their personality and recognise them for who they really are, as opposed to who others would like them to be. Intrinsic worth is thus linked to individuality; and the recognition of the individuality of a person provides an almost automatic incentive for treating them respectfully, just as we would treat something that we recognise to be a unique piece of art more carefully and respectfully than something we consider to be a bag of waste.

Thus, while Waldron's and Baer's theories of dignity are superficially very different, they both flesh out the idea of the high and intrinsic value of each person: Waldron through the idea of a high rank comparable to that of a noble; Baer through an acknowledgement of the individuality of each person. To repeat, this is not the place to resolve one of the deepest puzzles of legal, political, moral, and theological inquiry. But even with this sketchy account of intrinsic value, we can shed some light on the practice of contemporary human and constitutional rights law.

Perhaps the most obvious application is the prohibition of slavery: ${ }^{50}$ assigning to someone the very low status of a slave is incompatible with the high rank (comparable to that of a noble) that for Waldron lies at the core of dignity.

A similar idea applies to the prohibition of degrading treatment or punishment ${ }^{51}$ degradation implies a loss in status, and it is precisely the high social rank or status of every person that prohibits such acts. This explains why the prohibition of degrading treatment captures even acts which in isolation do not necessarily have devastating consequences for the affected individual (in contrast to, for example, acts of torture and many instances of inhuman treatment), such as a slap in the face by a police officer: ${ }^{.2}$ the specific evil is not about the consequences for the affected individual but about the denial of their high social rank. While noblemen, too, have to obey the law and can be punished if they fail to do so, ${ }^{53}$ their high social rank requires respectful treatment.

The prohibition of inhuman treatment or punishment and the prohibition of torture $^{54}$ invite, I believe, an analysis along Baer's conception of dignity. Inhuman treatment can be defined as treatment that no human being can reasonably be expected to endure. ${ }^{55}$ Thus, identifying what treatment is inhuman requires some attunement to the needs, the vulnerability, and the suffering of

50. See for example, Council of Europe, European Convention for the Protection of Human Rights and Fundamental Freedoms, as amended by Protocols Nos. 11 and 14, 4 November 1950, ETS 5 at Article 4, online at https://www.refworld.org/docid/3ae6b3b04.html [ECHR].

51. An aspect of ECHR, ibid at Article 3. In its more recent case law, the European Court of Human Rights has stressed that "the prohibition of torture and inhuman or degrading treatment or punishment is a value of civilisation closely bound up with respect for human dignity"; see Bouyid v Belgium, (2016), 62 EHRR 32 at para 81 [Bouyid]. In the same judgment, the Court also held at para 90 that "there is a particularly strong link between the concepts of 'degrading' treatment or punishment within the meaning of Article 3 of the Convention and respect for 'dignity.",

52. Ibid.

53. Waldron, supra note 48 at 64 : "[E]veryone who is punished is to be punished now as though he were an errant noble rather than an errant slave."

54. Another aspect of ECHR, supra note 50 at Article 3.

55. Jeremy Waldron, "Cruel, Inhuman, and Degrading Treatment: The Words Themselves" (2010) 23 Can JL \& Jur 269 at 280. 
the other person (and therefore also some attunement to one's own needs, vulnerability, and potential or actual suffering). Thus, it requires seeing the other person not in the way that one would perhaps prefer to see them: as a despicable criminal, or as someone who is just a nuisance. Rather, it requires seeing them, and therefore acknowledging them, as a person with a specific vulnerability, and one that is shared by all humans. Once this vulnerability is acknowledged, the impermissibility of treating them in inhuman ways becomes obvious.

The right to a fair trial ${ }^{56}$ in general and the right to a hearing in particular, too, can be illuminated by Waldron's and Baer's conceptions of dignity. Under Waldron's conception, it is clear that someone of the high social rank as a noble must be treated fairly and respectfully by the judicial system: it may be permissible to gloss over the legitimate interests of lowly persons, but certainly not of noblemen. This requires that they are given the opportunity to explain themselves. ${ }^{57}$ Along the lines of Baer's conception, it is crucial to acknowledge the person for who they really are and not for who we think they might be or who we would like them to be. This, however, plainly requires giving them the opportunity to present their case and their point of view; thus, a right to a hearing is required.

It seems unlikely that the above examples exhaust the reach of the principle of intrinsic value into human and constitutional rights law. We will see in the next sections that the dignitarian principles of moral autonomy and fundamental equality are much better understood than the idea of intrinsic value. This imbalance indicates that in order to make further progress with uncovering the 'deep structure' of human and constitutional rights, the dignitarian idea of intrinsic value may be the place to go.

\section{Moral autonomy}

Despite the difficulties of coming up with an account of dignity, let alone a reasonably uncontroversial one, there is far-reaching agreement that human dignity requires acknowledging and respecting human freedom, liberty, or autonomy (for present purposes I will treat these concepts as synonymous).$^{58}$ These concepts are very abstract and open to different interpretations, for example the freedom to do as one pleases ${ }^{59}$ the freedom to pursue one's projects in certain, important areas

56. For example, ECHR, supra note 50 at Article 6.

57. Waldron, supra note 48 at 54: "Law, we can say, is a mode of governance that acknowledges that people likely have a view or perspective of their own to present on the application of a social norm to their conduct. Applying a norm to a human individual ... involves paying attention to a point of view. In this way it embodies a crucial dignitarian idea-respecting the dignity of those to whom the norms are applied as beings capable of explaining themselves."

58. See e.g. Weinrib, supra note 1 at 7: "[T] he concept [of human dignity] concerns the equal right of each person to freedom." There is also an autonomy-denying interpretation of human dignity, according to which dignity requires dignified behaviour and thus authorises moralism. On this, see, from a critical perspective, Michael Rosen, "Dignity: The Case Against" in C McCrudden, ed, Understanding Human Dignity (Oxford University Press, 2013) 143 at 149-52; Baer, supra note 49 at 457-59.

59. As in the German interpretation of Article 2(1) of the Basic Law as protecting a right to freedom of action. See the text accompanying note 13 . 
of one's life, ${ }^{60}$ or the freedom to set and pursue one's own goals. ${ }^{61}$ It is this latter conception which today is most often associated with human dignity, most prominently and to my mind most convincingly in Dworkin's later work.

The second principle [of human dignity] — the principle of personal responsibility - holds that each person has a special responsibility for realising the success of his own life, a responsibility that includes exercising his judgment about what kind of life would be successful for him. He must not accept that anyone else has the right to dictate those personal values to him or impose them on him without his endorsement. He may defer to the judgments codified in a particular religious tradition or to those of religious leaders or texts or, indeed, of secular moral or ethical instructors. But that deference must be his own decision; it must reflect his own deeper judgment about how to acquit his sovereign responsibility for his own life. ${ }^{62}$

Dworkin's argument about personal responsibility captures an intuition that almost everyone will share. The view that I hold with regard to myself, and which I suspect virtually everyone holds with regard to themselves, is that it is not the state's business to get involved in the ethical choices that I make, for example by prohibiting my actions on the grounds that I am making ethically wrong, problematic, or worthless choices. But if we hold this view with regard to ourselves, then coherence requires that we also accept that everyone else has the right to live free from moralism and (hard ${ }^{63}$ ) paternalism.

The paradigmatic example of a law violating moral autonomy, and indeed the political issue which sparked much of the discussion about moralism in the 1960s, was the prohibition of homosexual sex on the ground of its assumed immorality. ${ }^{64}$ The view that came to prevail is that independently of whether homosexual sex is ethically valuable or worthless, it is within the freedom of each

60. As proposed, for example, in James Griffin's theory of human rights as protections of personhood. See James Griffin, On Human Rights (Oxford University Press, 2008) at 33-37. See further the following famous statement by the plurality (O'Connor, Kennedy, and Souter JJ) in Planned Parenthood v Casey (1992), 505 US 833 at 851, which also stresses the link between dignity and autonomy: "Our law affords constitutional protection to personal decisions relating to marriage, procreation, contraception, family relationships, child rearing, and education ... These matters, involving the most intimate and personal choices a person may make in a lifetime, choices central to personal dignity and autonomy, are central to the liberty protected by the Fourteenth Amendment. At the heart of liberty is the right to define one's own concept of existence, of meaning, of the universe, and of the mystery of human life. Beliefs about these matters could not define the attributes of personhood were they formed under compulsion of the State."

61. Weinrib, supra note 1 at 7: "As free, each person has the right to determine the purposes that he or she will pursue."

62. Dworkin, Is Democracy Possible Here?, supra note 17 at 10.

63. Hard (or deep) paternalism can be defined as imposing ethical values on a person, whereas soft (or superficial) paternalism is based on plausible assumptions about what a person's values actually are. A paradigmatic example of the latter category would be seatbelt laws. See ibid at 73 .

64. See the famous Hart-Devlin debate, with HLA Hart taking the liberal and Patrick Devlin the conservative position: HLA Hart, Law, Liberty, and Morality (Stanford University Press, 1963); Patrick Devlin, The Enforcement of Morals (Oxford University Press, 1959). 
agent to choose. ${ }^{65}$ However, the relevance of the idea of moral autonomy goes far beyond the protection of homosexual sex or even sexual freedom more broadly. ${ }^{66}$ It requires that any burden that the state imposes on a person cannot be justified by pointing to the ethical worthlessness of the person's behaviour. For example, speech cannot be restricted on the grounds of the wrongness or unattractiveness of the ideas expressed; ${ }^{67}$ religious practice cannot be prohibited or religious symbols advocated on the grounds of the rightness or the wrongness of the belief at stake; private choices cannot be prohibited on the grounds of disagreement about their ethical value, ${ }^{68}$ etc. More generally, moralism and (hard) paternalism - that is, basing the state's policies on views about the ethical value of certain acts or beliefs-are impermissible.

In the context of human and constitutional rights adjudication, the moral autonomy principle finds a well-established manifestation in the 'legitimate goal' stage of the proportionality test. Its function is to separate legitimate considerations that are in principle relevant for the justification of a policy-such as protecting other people's rights, or protecting certain public goods-from considerations which are illegitimate and which therefore have no role to play in the justification of a policy. Goals that violate the dignitarian principle of moral autonomy, that is, moralistic or paternalistic goals, are excluded at this stage; this ensures that the following steps of the proportionality analysis examine whether the policy at stake can be justified in light of legitimate considerations. ${ }^{69}$

To return to the example regarding assisted suicide introduced in the previous section, ${ }^{70}$ a properly conducted proportionality analysis excludes at the legitimate goal stage any goal that is related to ethical (including religious) disapproval of assisted suicide ('It is immoral/against God's will to assist someone with taking

65. See Dudgeon v The United Kingdom (1982), 4 EHRR 149 at para 61: “'Decriminalisation' does not imply approval." See further Lawrence v Texas (2003), 123 S. Ct. 2472 at 2484: "The petitioners are entitled to respect for their private lives. The State cannot demean their existence or control their destiny by making their private sexual conduct a crime. Their right to liberty under the Due Process Clause gives them the full right to engage in their conduct without intervention of the government."

66. For other cases involving sexual freedom, see Laskey, Jaggard, and Brown v The United Kingdom (1997), 24 EHRR 39 (sado-masochistic orgies); Stübing v Germany (2012), 55 EHRR 24 (incest).

67. See e.g. Texas v Johnson (1989), 491 US 397 at 414: "If there is a bedrock principle underlying the First Amendment, it is that the government may not prohibit the expression of an idea simply because society finds the idea itself offensive or disagreeable." See also the European Court of Human Rights' famous statement in Handyside $v$ The United Kingdom (1979-80), 1 EHRR 737 at 744: "Freedom of expression constitutes one of the essential foundations of such a society, one of the basic conditions for its progress and for the development of every man. Subject to Article 10 (2), it is applicable not only to 'information' or 'ideas' that are favourably received or regarded as inoffensive or as a matter of indifference, but also to those that offend, shock or disturb the State or any sector of the population. Such are the demands of that pluralism, tolerance and broadmindedness without which there is no "democratic society."'

68. For example, one aspect of the debate about whether there is a right to abortion is whether the state can take the view that the fetus constitutes human life, or whether doing so would be moralistic and it is the pregnant woman's view that should prevail.

69. Kumm, "Political Liberalism", supra note 4 at 142-48; Möller, The Global Model, supra note 1 at 183-93.

70. See Section III.2, above. 
their life, and therefore it should be prohibited'), but it allows the goal of protecting vulnerable people from abuse ('If we allow assisted suicide, this creates the risk of people being bullied into committing suicide'). The analysis at the next three stages (suitability/rational connection, necessity, balancing/proportionality in the strict sense) then examines whether the remaining, legitimate, goal of protecting vulnerable people from abuse justifies the policy of prohibiting assisted suicide. Gorsuch's view that assisted suicide should be prohibited because it violates the intrinsic value of human life is moralistic and therefore inconsistent with the dignitarian structure of rights: it is not permissible for the state to override the right-holder's judgment regarding the value of their life.

While the basic idea of moral autonomy and its application in human and constitutional rights law is well understood, its full potential has not been uncovered yet. I will just point to one issue which is surprisingly under-theorised, namely the relationship between moral autonomy and cultural arguments. It is always possible to 'repackage' a moralistic argument as a cultural one: if an (assumedly) worthless individual choice is repeated often enough by a sufficiently large number of people, it will have an effect on the public culture. For example, instead of proposing the prohibition of homosexual sex because of its assumed immorality, one might claim that permitting homosexual sex and normalising homosexuality have a harmful effect on society's commitment to the traditional family structure; instead of prohibiting assisted suicide as being against God's will, one might argue that allowing assisted suicide will lead to a decline of respect for human life in society; instead of restricting the right of Muslim women to wear the hijab on the grounds of being a worthless personal choice, one points to the harm that such acts may pose to a societal commitment to gender equality. Apart from a short section in Dworkin's book Is Democracy Possible Here?, ${ }^{71}$ this issue has received surprisingly little scholarly attention. My goal here is not to propose a solution but merely to point out an important and unresolved issue related to the proper reach of the dignitarian principle of moral autonomy.

\section{Fundamental equality}

It is uncontroversial that human dignity requires respect for the fundamental equality of all humans. As a matter of the history of ideas, one important source of this view is the Christian idea of imago Dei: the idea that humans are made in the image of God. It means that all humans have a divine 'spark' within them which is the basis of their unique and very high value and which also implies that in this regard all humans are fundamentally equal. We can see here that there is a close connection between the principle of intrinsic value and the principle of

71. Dworkin accepts that culture influences the views and choices that people make, but he insists that the collective and deliberate manipulation of the culture is impermissible. See Dworkin, Is Democracy Possible Here?, supra note 17 at 76. 
fundamental equality, ${ }^{72}$ and hence it is perhaps not surprising that Dworkin lumps the two together in his first principle of human dignity. ${ }^{73}$ Nevertheless I propose to treat them as distinct because their manifestations in human and constitutional rights law are different: the principle of intrinsic value is about the ways in which an actor (in the present context, usually the state) may treat a person, whereas the principle of equality is concerned with how an actor (the state) may treat one person vis-à-vis another. Take the example of slavery, which violates both the principle of intrinsic value and the principle of fundamental equality. Slavery is inconsistent with the principle of intrinsic value because a state that designates someone as a slave fails to treat him as having a high status, as someone who fundamentally matters and whose fate is, we might say, of cosmic importance. Slavery further violates the principle of fundamental equality because in a state that endorses slavery, there are not only slaves but also slaveholders, and the relationship between the two is inconsistent with every human's equal importance.

Thus, the principle of fundamental equality is concerned with the equal standing of persons relative to one another. This idea is very abstract and can be interpreted, and has been interpreted, in more than one way. A minimalistic, narrow interpretation would prohibit unjustified discrimination on the grounds of certain protected characteristics such as race, sex, sexual orientation, faith, etc. By contrast, a broad interpretation would include what is known in constitutional law as a general equality clause which prohibits any unjustifiable treatment of one person or group vis-à-vis another, independently of whether a protected characteristic is at stake; this is the position taken by the German Federal Constitutional Court with regard to Article 3(1) of the Basic Law. ${ }^{74}$ The underlying rationale of this view strikes me as better in tune with the dignitarian principle of equal importance because the protected characteristics used by the narrow approach are, to my mind, just pointers to areas where history teaches us that unjustifiable discrimination often occurs; but they carry no moral significance beyond that. Put differently, violations of fundamental equality occur also, even though perhaps less frequently, in areas unrelated to protected characteristics. Thus, the dignitarian requirement of respect for people's fundamental equality requires the comprehensive protection offered by a general right to equality along the lines of the German approach.

72. See Janet Soskice, "Human Dignity and the Image of God" in C McCrudden, ed, Understanding Human Dignity (Oxford University Press, 2013) 229 at 231-32: "[Imago Dei] has been the basis in Christian teaching for regarding every human being, no matter how poor, burdened, restricted, ragged, or dissolute, as entirely distinctive and worthy of reverence." See also David P Gushee, "A Christian Theological Account of Human Worth" in C McCrudden, ed, Understanding Human Dignity (Oxford University Press, 2013) 275 at 278: "Further, God is equally the Creator of all humans ... There is one God who makes one humanity. This is a pivotal element of biblical creation theology, and it contributes at least an implicit primal human equality and unity" [emphasis in original].

73. See the text accompanying note 47.

74. Basic Law for the Federal Republic of Germany, Article 3(1): "All persons shall be equal before the law." 
In the example of same sex marriage put forward in the previous section, ${ }^{75}$ the emerging consensus in the Western world is that the principle of fundamental equality requires the availability of same sex marriage. In short, it is seen, correctly to my mind, as unjustifiable for the state to provide the institution of marriage, with all its symbolic and concrete benefits, in a way that makes it available only to people of a heterosexual but not for those of a homosexual orientation. I should add that when reasonable people hold a view that conflicts with the demands of fundamental equality, this is almost never because they dispute the principle as such; only the most hardened racists, sexists, homophobes, etc., do that. Rather they make a moral mistake when applying the abstract principle to a specific situation. Finnis' mistake lies in his view that the state can justifiably discriminate between people in order to promote ethically valuable lifestyles (and he believes that only heterosexual marriage is ethically valuable), whereas dignity insists that such discrimination is impermissible because judgment on the ethical value of a lifestyle lies within the personal responsibility of the person whose life it is. So the proper analysis of the issue of same sex marriage (and many other issues of non-discrimination) will involve both the principle of moral autonomy and the principle of fundamental equality.

Importantly, fundamental equality manifests itself not only with regard to the right to equality and the right to non-discrimination, but also in the application of the proportionality test. The suitability, necessity, and balancing stages of the proportionality test are concerned with fundamental equality. I have developed this point in an earlier paper ${ }^{76}$ and will briefly summarise my argument here, because it is important for appreciating the interplay between the principles of moral autonomy and fundamental equality and the structure of human and constitutional rights. A state that limits a right-holder's right usually does so in order to benefit other people (or the public more generally). In a scenario where the burden on the right-holder is disproportionate in the strict sense (thus, it fails at the balancing stage of the proportionality test), the state made a mistake by placing a burden on the right-holder that is too severe, relative to the benefits that arise for others or the public. Had it imposed a less restrictive burden, or had the benefits for others or the public been greater, the measure might have been justified. Thus, by burdening the right-holder 'too much,' it did not attach sufficient weight to individual legitimate interests relative to other people's interests, and it thus did not treat individual interests as equally important as everyone else's. This constitutes a violation of fundamental equality.

As an illustration, take the case of Odièvre $v$ France, where the ECtHR held by a narrow margin that France's policy of allowing women to release their children for anonymous adoption did not violate Article 8 ECHR (the right to private life) of the child. ${ }^{77}$ The question was whether the child, later in life, has a human right to be informed of her biological mother's identity. The relevant interests at

75. See Section III.2, above.

76. See Möller, "Dworkin's Theory of Rights", supra note 1 at 292-96.

77. Odièvre v France (2004), 38 EHRR 43. 
stake were the child's identity-related interest in finding out about her past, the biological mother's interest in remaining anonymous, a public interest in avoiding abortions, and the interests of a range of other actors, including the biological father, potential biological siblings, and the members of the adoptive family. Seven dissenting judges came to the conclusion that France's policy imposed a disproportionate burden on the applicant. To exemplify my point, let us assume for the sake of the argument that the dissenters were right. For them, the burden on the applicant was so severe that it was not outweighed by the interests of the biological mother, the adoptive family, and the public interest in avoiding abortions. Put differently, France attached too little weight to the identity-related interests of adopted children in finding out about their personal history, and it attached too much weight to the interests of, in particular, the biological mothers. Thus, France failed to attach sufficient weight to the legitimate interests of one group vis-à-vis another. As explained above, this is precisely what the dignitarian principle of fundamental equality prohibits.

\section{Dignity and the structure of rights}

This, then, is an outline of the dignitarian structure of human and constitutional rights: rights protect human dignity, that is, the principles of intrinsic value, moral autonomy, and fundamental equality. The principles of moral autonomy and fundamental equality manifest themselves primarily in the proportionality analysis. At the legitimate goal stage of the test, illegitimate goals, that is, moralistic and paternalistic goals that are incompatible with the principle of moral autonomy, are excluded in order to ensure that they play no role in the justification of the policy. The subsequent suitability, necessity, and balancing stages are concerned with fundamental equality: they ensure that a policy does not impose a burden on a person which treats their individual interests as less important than other people's.

Absolute rights (which identify areas where proportionality does not apply) are often concerned with giving effect to the principle of intrinsic value. Thus, certain forms of treating people that are inconsistent with their high moral status are categorically impermissible; this includes torture, inhuman or degrading treatment or punishment, slavery, and forced labour. Procedural rights such as the right to a fair trial also follow primarily from the principle of intrinsic value which requires treating every person as someone whose views and interests fundamentally matter and who must therefore be treated in accordance with fair procedures.

The above should not be read as a schematic way of mapping certain moral principles onto certain legal doctrines. Thus, my claim is not that the first stage of the proportionality test ought to be explained exclusively in terms of moral autonomy, the next three stages exclusively in terms of fundamental equality, and absolute rights exclusively in terms of intrinsic value. Rather, I offer the links between the three dignitarian principles and the respective doctrines and categories of rights as a rough categorisation that points to the dominant moral themes 
that are relevant in the respective contexts and suggests that there is no necessary tension or contradiction between regarding human dignity as the foundation of rights and the practice of rights adjudication with its categorisation of rights into absolute rights and rights subject to proportionate limitations.

\section{Conclusion}

The discussions about human and constitutional rights in the last twenty years have moved away from the formal theory of rights proposed by Alexy and towards substantively moral accounts. The view that has emerged is that the practice of rights adjudication is best explained in terms of the culture of justification or the right to justification, according to which the core of human and constitutional rights lies in a commitment to justification in terms of reasonableness or public reason. While this presents itself as a moral theory, I have shown that the reference to reasonableness and public reason conceals rather than reveals a number of further commitments. The goal of this article has been to uncover and make explicit these moral commitments, which I have labelled the dignitarian structure of human and constitutional rights with its principles of intrinsic value, moral autonomy, and fundamental equality.

If this has been successful, then we can now articulate a more appealing account of the culture of justification and the right to justification. The culture of justification as conventionally understood insists that every person is entitled to a reasonable justification for any burden placed on them by the state. This translates into the familiar doctrinal structure of a wide scope of prima facie rights coupled with the requirement that any interference with these rights must be proportionate, that is, reasonably justifiable. The conclusion of this essay is that the act in question must be reasonably justifiable to the individual as a human being with human dignity, that is, it must be reasonably justifiable in light of the dignitarian principles of intrinsic value, moral autonomy, and fundamental equality.

This may seem like a modest clarification, but its implications are considerable. Shifting the focus towards the three dignitarian principles allows us to address the nature of human and constitutional rights in general and specific rights issues in particular not (only) in the doctrinal framework of proportionality or the vague language of reasonableness, but (also) in the substantively moral language of the principles on which rights are based. Given that, as I have stressed above, fundamental rights, including those acknowledged by the positive law, are creatures of morality and must correspondingly be analysed in moral terms, this strikes me as the right approach from an intellectual perspective and also as one which holds the promise of a deeper and more meaningful engagement with both rights theory and specific rights issues. 